\title{
New characterizations of old bankruptcy rules
}

\author{
Nir Dagan \\ Department of Economics, the Hebrew University of Jerusalem, Mount Scopus, \\ 91905 Jerusalem, Israel
}

Received: 27 June 1994/Accepted: 29 December 1994

\begin{abstract}
This paper presents axiomatic characterizations of two bankruptcy rules discussed in Jewish legal literature: the Constrained Equal Awards rule and the Contested Garment principle (the latter is defined only for two-creditor problems.) A major property in these characterizations is independence of irrelevant claims, which requires that if an individual claim exceeds the total to be allocated the excess claim should be considered irrelevant.
\end{abstract}

\section{Introduction}

The bankruptcy problem deals with the problem of how to divide an estate among all creditors when the estate is insufficient to meet the deceased's debts. This problem was addressed by Jewish scholars at least since the era of the collation of the Talmud. Various allocations rules were proposed, some supported by legal reasoning. Two of the best known rules are the Constrained Equal Awards (CEA) rule and the Contested Garment (CG) principle. The first divides the estate equally among the creditors provided that no one gets more than his claim. This rule was accepted as law by most important rabbinical authorities. The Contested Garment principle, which is defined only for two-creditor problems, gives each creditor the part of the estate conceded to him by the other creditor, and divides the remaining contested amount equally ${ }^{1}$.

O'Neill (1982) suggested that the bankruptcy problem could be analyzed by game-theoretic methods. He proposed a formal presentation of the problem and gave an axiomatic treatment of rules that appear in rabbinical sources. In addition he proposed a TU game that represents the bankruptcy problem. By applying the

The author gratefully acknowledges helpful conversations with Oscar Volij.

${ }^{1}$ The Contested Garment principle was recommended for situations which are considered distinct from the bankruptcy problem presented here, and therefore the fact that the two-creditor CEA rule is different from this principle does not constitute a contradiction in Jewish law. 
Shapley value to this game, O'Neill generated a rule that generalizes the CG principle to any $n$-creditor bankruptcy problem. Aumann and Maschler (1985) applied the nucleolus to the TU game mentioned above and generated a new bankruptcy rule. They showed that their rule recommends the same allocations recommended by Rabbi Nathan some two thousand years ago to the three particular cases he considered. Moreover, they argued that it is most likely that Rabbi Nathan had in mind the rule induced by nucleolus. Aumann and Maschler support this conjecture by showing that their rule is closely related to two other rules discussed in Jewish legal literature: the Contested Garment principle and the Constrained Equal Awards rule.

In this paper we provide axiomatic characterizations of the latter two rules. A property common to both these rules is that any individual claim that exceeds the total to be allocated is considered irrelevant. We claim that this property and other properties used in the characterizations are inspired by legal principles mentioned in the Talmudic literature.

Since the rule suggested by Aumann and Maschler (1985) can be characterized by combining the CG principle with a consistency requirement, our characterizations of the CG principle induce characterizations of Aumann and Maschler's rule as well.

In the next section we present the basic problem that appears in the Talmud. In Section 3 we present the formal model. An axiomatic characterization of the CEA rule is derived in Section 4. Then we study the CG principle and present two axiomatic characterizations of this rule (Section 5). Section 6 concludes.

\section{The basic problem}

In the Talmud (Ketuboth, 93a) the following problem is considered: A man died and left three widows whose claims on the deceased's estate are one hundred, two hundred, and three hundred, respectively. Unfortunately. the estate is less than six hundred. Rabbi Nathan considered three cases: in one the estate is a hundred, in the second the estate is two hundred, and in the third it is three hundred. The divisions he proposed are summarized in Table 1 below.

Table 1

\begin{tabular}{llll}
\hline \multirow{4}{*}{ Estate } & \multicolumn{3}{l}{ Claims } \\
\cline { 2 - 4 } & 100 & 200 & 300 \\
\hline 100 & $33 \frac{1}{3}$ & $33 \frac{1}{3}$ & $33 \frac{1}{3}$ \\
200 & 50 & 75 & 75 \\
300 & 50 & 100 & 150 \\
\hline
\end{tabular}

Rabbi Nathan did not explain the general principle underlying these recommendations. This led to many discussions, some trying to explain Rabbi Nathan's recommendations and some proposing other rules.

\section{The formal model}

A bankruptcy problem is a pair $(E, \mathbf{c})$ where $\mathbf{c}=\left(c_{1}, \ldots, c_{n}\right) \geq \mathbf{0}$, and $0 \leq E \leq \sum_{i=1}^{n}$ $c_{i} . E$ represents the total value of the estate and $\mathbf{c}$ is the vector of the creditors' 
claims. The sum of these claims is denoted by $C$. An allocation in such a problem is an $n$-tuple $\mathbf{x}=\left(x_{1}, \ldots, x_{n}\right) \in \mathbb{R}^{n}$ with $\sum_{i=1}^{n} x_{i}=E$ and $0 \leq x_{i} \leq c_{i}, i=1, \ldots, n$. A rule is a function that assigns a unique allocation to each bankruptcy problem. We denote the set of all creditors by $N$.

\section{The Constrained Equal Awards rule}

We begin with a comment of a scholar called Rabbi ${ }^{2}$. He said "I do not approve of Rabbi Nathan's views in these [cases] for [the three wives] take equal shares." Rashi $^{3}$ claimed that Rabbi suggested the Constrained Equal Awards (CEA) rule which is defined as follows: $C E A(E, \mathbf{c})=\mathbf{x}$, where $x_{i}=\min \left\{\lambda, c_{i}\right\}$ and $\lambda$ solves the equation $\Sigma_{i \in N} \min \left\{\lambda, c_{i}\right\}=E^{4,5}$.

The CEA rule was accepted as law by most important rabbinical authorities including Maimonides ${ }^{6}$.

Now we present and discuss the properties that characterize CEA rule:

Independence of irrelevant claims: A rule $f$ satisfies independence of irrelevant claims, if for all bankruptcy problems $(E, \mathbf{c}), f(E, \mathbf{c})=f\left(E, \mathbf{c}^{E}\right)$, where $c_{i}^{E}=\min$ $\left\{c_{i}, E\right\}$ and $\mathbf{c}^{E}=\left(c_{i}^{E}, \ldots, c_{n}^{E}\right)$.

The major argument in favor of this property is that one cannot claim more than there is; thus the excess of a claim above the estate is irrelevant. A rule is independent of irrelevant claims if it allocates the estate taking into account only the relevant claims.

Rasag $^{7}$ in explaining Rabbi Nathan's recommendations (recall Table 1 in Section 2), says: "... every widow that the estate is less than her claim is not preferred relative to the one that precedes her ... Therefore, when the estate is a hundred, that is less than the claims of the second and the third, they are not preferred relative to the first, and thus all three split equally; and when the estate is two hundred ... the third is not preferred relative to the second, but each takes seventy-five."

An indirect evidence that the principle of independence of irrelevant claims was widely accepted is the fact that almost no one in Jewish rabbinical lore expressed any objection, or provided a lengthy explanation, to the division recommended by Rabbi Nathan to the case of an estate of a hundred. It is clear that the CEA rule satisfies independence of irrelevant claims as for all $\lambda \leq E$, $\min \left\{\lambda, c_{i}\right\}=\min \left\{\lambda, c_{i}^{E}\right\}$.

Now, we turn to another property satisfied by the CEA rule.

\footnotetext{
2 It appears in Ketuboth 93a, see the English translation of the Babylonian Talmud edited by Epstein (1936, Vol. 2, p. 592).

${ }^{3}$ Rabbi Shelomo Yitshaki (1040-1105). His interpretation may be found in most editions of the Talmud, e.g., Steinsaltz (1985).

${ }^{4}$ This equation has a unique solution when $C>E$. If $C=E$, any solution $\lambda$ is greater than or equal to the maximum claim and therefore $x_{i}=c_{i}$ for all $i$.

${ }^{5}$ Some others interpreted Rabbi's rule as the proportional rule.

${ }^{6}$ Rabbi Moshe ben Maimon (1138-1204), quoted in Levine (1939, Vol. 8, p. 311).

${ }^{7}$ Rabbi Seadiya Gaon (882-942), quoted in Levine (1939, Vol. 8, p. 310). The translation to English is my own.
} 
Composition: A rule $f$ satisfies composition if for all bankruptcy problems $(E, \mathbf{c})$, and for all $0 \leq E^{\prime} \leq E, f\left(E^{\prime}, \mathbf{c}\right)=\mathbf{x}$ implies $f(E, \mathbf{c})=\mathbf{x}+f\left(E-E^{\prime}, \mathbf{c}-\mathbf{x}\right)$.

A rule satisfies composition if it permits division of part of the estate, and then division of the reminder with respect to the outstanding claims.

The idea that the estate may be divided in steps can be found in Rabina, ${ }^{8}$ who claimed that Rabbi Nathan's recommendations in the cases of 200 and 300 are a result of two-stage division. Rashi, interpreting Rabina, proposed a rule which does not satisfy composition ${ }^{9}$. By choosing $E^{\prime}=75$, and applying this rule in steps one gets the divisions recommended by Rabbi Nathan. Clearly, if the courts apply two-step divisions, as Rashi assumed, the composition property of rules is of interest.

Composition appears also in Young's (1988, Theorem 1) characterization of equal sacrifice taxation methods.

The next axiom is a natural symmetry requirement.

Equal treatment: A rule satisfies equal treatment if it always assigns equal awards to creditors with equal claims.

It turns out that the above three axioms characterize the CEA rule. Formally:

Proposition 1. The CEA rule is the unique rule that satisfies independence of irrelevant claims, composition, and equal treatment.

Proof. We will prove only the uniqueness part.

Note that if a rule satisfies composition it is monotone in the sense that if the estate becomes larger, no creditor is worse off.

Let $(E, \mathbf{c})$ be a bankruptcy problem. Assume without loss of generality that creditors are indexed by the order of their claims, i.e., $0 \leq c_{1} \leq c_{2} \leq \ldots \leq c_{n}$.

Now, let $f$ be a rule that satisfies independence of irrelevant claims, composition, and equal treatment. Consider the case in which $E \leq c_{1}:=E_{1}$. By independence of irrelevant claims and equal treatment the estate is split equally, thus $f(E, \mathbf{c})=C E A(E, \mathbf{c})$. Now consider the case in which $E \leq c_{1}+c_{1}(1-1 / n):=E_{2}$. By composition and the previous step $f(E, \mathbf{c})=\mathbf{x}+f\left(E-E_{1}, \mathbf{c}-\mathbf{x}\right)$, where $\mathbf{x}=C E A\left(E_{1}, \mathbf{c}\right)$. Note that $E-E_{1} \leq c_{1}(1-1 / n)=c_{1}-x_{1}$. Thus, by independence of irrelevant claims and equal treatment the amount $E-E_{1}$ is split equally thus $f\left(E-E_{1}, \mathbf{c}-\mathbf{x}\right)=C E A\left(E-E_{1}, \mathbf{c}-\mathbf{x}\right)$, and $f(E, \mathbf{c})=C E A(E, \mathbf{c})$. Now, we can repeat the same argument finitely many times and show that $f(E, \mathbf{c})=C E A(E, \mathbf{c})$ for all $E<n c_{1}$. By the monotonicity of $f$ this holds also for $E=n c_{1}$. Now the whole argument may be applied to show that $f(E, \mathbf{c})=C E A(E, \mathbf{c})$ for all $E<n c_{1}+(n-1)\left(c_{2}-c_{1}\right)$. This may be repeated until all possible estates are covered. Q.E.D.

\section{The Contested Garment principle}

In this section we discuss a problem whose relation to the bankruptcy problem, presented in Sect. 2, will become clear towards the end of the section.

\footnotetext{
${ }^{8}$ See the Gemara of Ketuboth 93a, Epstein (1936, Vol. 2, p. 591).

${ }^{9}$ More references concerning this rule may be found in Aumann and Maschler (1985, Sect. 4 and footnote 14).
} 
Various Talmudic studies discussed by Aumann and Maschler (1985), consider an idea of duality of rules. A dual of a rule $f$ is the rule that assigns awards in the same manner as $f$ assigns losses. Let $f$ be a rule. The dual of $f$ is the rule that assigns each bankruptcy problem $(E, \mathrm{c})$ the allocation $\mathbf{c}-f(C-E, \mathbf{c})^{10}$. Some division problems (not necessarily bankruptcy problems) have a natural interpretation of division of awards, and some division problems have a natural interpretation of division of losses. Now, it may be desired that rules applied to various problems be compatible in the sense that if a rule is used in the division of awards, its dual should be used in the division of losses. If one considers both interpretations natural in bankruptcy problems and accepts the above idea, then one must require bankruptcy rules to coincide with their duals. Formally we define:

Self-duality: A rule $f$ is a self-dual if for all bankruptcy problems $(E, \mathbf{c}), f(E, \mathbf{c})=$ $\mathbf{c}-f(C-E, \mathbf{c})$.

A self-dual rule allocates awards and losses in the same manner. The CEA is clearly not self-dual. Are there any rules that are both self-dual and independent of irrelevant claims? The answer is yes. Indeed, the rule O'Neill (1982) generated from the Shapley value, Aumann and Maschler's (1985) Contested Garment Consistent rule, and the Adjusted Proportional rule introduced by Curiel et al. (1988) all satisfy these two properties. In two-creditor problems these three rules coincide with a Talmudic rule known as the Contested Garment (CG) principle, defined as follows ${ }^{11}$ :

$$
C G\left(E,\left(c_{i}, c_{j}\right)\right)=\left[\frac{E+c_{i}^{E}-c_{j}^{E}}{2}, \frac{E+c_{j}^{E}-c_{i}^{E}}{2}\right]
$$

In turns out, that when confined to two-creditor problems, self-duality and independence of irrelevant claims characterize the CG principle. This is stated formally as follows:

Proposition 2. The Contested Garment principle is the unique two-creditor rule that satisfies self-duality and independence of irrelevant claims.

Proof. We will prove only the uniqueness part. Let $\left(E,\left(c_{i}, c_{j}\right)\right)$ be a bankruptcy problem, and let $f$ be a self-dual and an independent of irrelevant claims rule. Without loss of generality, there are three cases: (a) $c_{i} \leq E \leq c_{j}$, (b) $E \leq c_{i} \leq c_{j}$, and (c) $c_{i} \leq c_{j} \leq E$.

Case (a) $c_{i} \leq E \leq c_{j}$. Let $c_{j}^{\prime}=2 E-c_{i}$. Note that $c_{j}^{\prime} \geq E$. Consider the bankruptcy problem $\left(E,\left(c_{i}, c_{j}^{\prime}\right)\right)$. By independence of irrelevant claims.

$$
f\left(E,\left(c_{i}, c_{j}\right)\right)=f\left(E,\left(c_{i}, E\right)\right)=f\left(E,\left(c_{i}, c_{j}^{\prime}\right)\right) .
$$

Further note that, $c_{i}+c_{j}^{\prime}-E=E$. Thus, by self-duality,

$$
f_{i}\left(E,\left(c_{i}, c_{j}^{\prime}\right)\right)=c_{i}-f_{i}\left(E,\left(c_{i}, c_{j}^{\prime}\right)\right)
$$

\footnotetext{
${ }^{10}$ Recall that $C$ is the sum of the claims.

${ }^{11}$ This definition is equivalent to Aumann and Maschler's (1985), and generalizes the Talmudic principle which is not defined for all two-creditor problems.
} 
or

$$
f_{i}\left(E,\left(c_{i}, c_{j}^{\prime}\right)\right)=c_{i} / 2
$$

(1) and (3) imply

$$
f_{i}\left(E,\left(c_{i}, c_{j}\right)\right)=c_{i} / 2 \text {. }
$$

This concludes the proof for case (a).

Case (b) $E \leq c_{i} \leq c_{j}$. By independence of irrelevant claims, $\left.f\left(E, c_{i}, c_{j}\right)\right)=$ $f(E,(E, E))$. Since $E \leq E \leq E,(E,(E, E))$ belongs to case (a), which is already solved, thus the proof for case (b) is completed.

Case (c) $c_{i} \leq c_{j} \leq E$. By self-duality, $f\left(E,\left(c_{i}, c_{j}\right)\right)=\mathbf{c}-f\left(C-E,\left(c_{i}, c_{j}\right)\right)$. Note that $\left(C-E,\left(c_{i}, c_{j}\right)\right)$ is in case (b), which is already solved. This concludes the proof. Q.E.D.

Although the axioms in Proposition 2 are inspired by Talmudic principles, the rationale given for this rule is quite different. The contested garment problem appears in the Talmud (Baba Mezia, 2a). The problem is as follows: Two people contest ownership of a garment, both claiming that it is partly (or entirely) theirs. The parts they claim total more than one. This problem is similar to the bankruptcy problem but differs from it in two respects. One is that in the garment problem it impossible for both claims to be true, but if we assume that both claims are identically credible this difference may be ignored. Another difference is that in the garment problem no one can claim more than the whole garment by definition, whereas in the bankruptcy problem this is possible. As the Talmudic CG principle is described for a case in which no one claims more than the whole, the definition given above generalizes the principle to all two-creditor problems by assuming independence of irrelevant claims. Rashi explained the CG principle by considering the case of one person claiming the whole and the other claiming half, upon which the one who claims half agrees that the other half belongs to the other claimant. Thus, the one who claims the whole is to receive the latter half. The first half, which is claimed by both, is divided equally. Rashi's explanation inspires the following formal discussion: For each ( $n$-creditor) bankruptcy problem $(E, c)$ and creditor $i$, define

$$
v_{i}^{(E, c)}=\max \left\{0 ; E-\sum_{j \neq i} c_{j}\right\} .
$$

$v_{i}^{(E, c)}$ is the amount of money conceded to creditor $i$ by all other creditors. Whenever there is no danger of confusion we write $v_{i}$ instead of $v_{i}^{(E, c)}$. In any allocation $\mathbf{x} v_{i} \leq x_{i}$, which means that $v_{i}$ is the minimum amount that can be assigned to $i$ by any rule ${ }^{12}$. The fact that any allocation assigns each player an amount greater than $v_{i}$ allows us to interpret $v_{i}$ as the maximum amount which everybody agrees is due to creditor $i$. No matter how the estate is divided among the creditors, there is complete agreement that each will receive at least $v_{i}$. This leads to the following property:

$v$-Separability: A rule $f$ is $v$-separable if for all bankruptcy problems $(E, \mathbf{c})$,

$$
f(E, \mathbf{c})=\mathbf{v}+f\left(E-\sum_{i \in N} v_{i}, \mathbf{c}-\mathbf{v}\right)
$$

where $\mathbf{v}=\left(v_{1}, \ldots, v_{n}\right)$. 
$v$-separability says that the problem can be solved in two steps: First give each creditor the amount conceded by the others and then apply the rule to the bankruptcy problem where the debts are reduced by $\mathbf{v}$ and the value of the assets is what remains after the first step.

It can be easily verified that $\left(E-\sum_{i \in N} v_{i}, \mathbf{c}-\mathbf{v}\right)$ is indeed a bankruptcy problem $^{12}$.

Now, let us return to the two-person garment problem. It is easily verified that when the maximum claim does not exceed the whole garment then in the second stage $\left(E-\sum_{i \in N} v_{i}, \mathbf{c}-\mathbf{v}\right)$, both creditors claim the whole, thus an equal split is sensible. In the general case both creditors claim at least the whole in this second stage, making the problem symmetric, if we accept the axiom of independence of irrelevant claims. This leads to the conclusion that creditor $i$ should get $v_{i}+\left(E-v_{i}-v_{j}\right) / 2$. The reader is invited to check that this formula is equivalent to the one in the definition of the CG principle.

The above discussion leads to another characterization of the CG principle:

Proposition 3. The CG principle is the unique two-creditor rule that satisfies $v-$ separability, independence of irrelevant claims and equal treatment.

The proof follows directly from the discussion that precedes the Proposition, and is therefore left to the reader.

Are the axioms used in Propositions 2 and 3 interdependent in the $n$-creditor case? The answer is that independence of irrelevant claims and self-duality imply $v$-separability, but do not imply equal treatment. The axioms of Proposition 3 do not imply self-duality. Formally:

Proposition 4. (a) If a rule is both independent of irrelevant claims and self-dual, then it is $v$-separable.

(b) There exists a rule that satisfies independence of irrelevant claims and selfduality, and does not satisfy equal treatment.

(c) There exists a rule that satisfies $v$-separability, independence of irrelevant claims, and equal treatment, and is not self-dual.

Proof. (a) Let $f$ be self-dual and independent of irrelevant claims. By self-duality, for all bankruptcy problems $(E, \mathbf{c}), f(E, \mathbf{c})=\mathbf{c}-f(C-E, \mathbf{c})$. By independence of irrelevant claims, $\mathbf{c}-f(C-E, \mathbf{c})=\mathbf{c}-f\left(C-E, \mathbf{c}^{C-E}\right)$. By applying self-duality again, we receive

$$
\mathbf{c}-f\left(C-E, \mathbf{c}^{C-E}\right)=\mathbf{c}-\left\{\mathbf{c}^{C-E}-f\left[\left(\sum_{i \in N} c_{i}^{C-E}(C-E)\right), \mathbf{c}^{C-E}\right]\right\}
$$

Now, note that

$$
c_{i}-c_{i}^{C-E}=c_{i}-\min \left\{c_{i}, C-E\right\}=\max \left\{0, E-C+c_{i}\right\}=v_{i} \text { for all } i .
$$

Substituting (5) in (4) gives the required result.

(b) Consider the rule that assigns each bankruptcy problem $(E, c)$ with the set of creditors $N=\{1,2,3\}$ the allocation $\mathbf{x}$, where $x_{1}=C G_{1}\left[E,\left(c_{1}, c_{2}+c_{3}\right)\right]$ and $\left(x_{2}, x_{3}\right)=C G\left[E-x_{1},\left(c_{2}, c_{3}\right)\right]$. This rule is self-dual and independent of irrelevant claims, but does not satisfy a symmetry property, weaker than equal treatment,

${ }^{12}$ A proof of this statement is given in Dagan and Volij (1993). 
that requires that if all creditors have equal claims they split the estate equally. For example, in the problem $(100 .(100,100,100))$ the recommended allocation is $(50,25,25)$.

(c) Consider the rule $f$ that is defined as follows: $f(E, \mathbf{c})=\mathbf{v}+C E A\left(E-\sum_{i \in N} v_{i}\right.$, c - v). Q.E.D.

It is clear that the CG principle does not satisfy composition. Does a self-dual rule that satisfies composition exist? Young (1988, Theorem 3) showed that the proportional rule is the unique rule that satisfies these two properties.

For the sake of completeness, we briefly discuss results concerning the analysis of Rabbi Nathan's puzzling recommendations. Pineles $(1861$, p. 64) discovered that Rabbi Nathan's recommendations coincide with the recommendations of the CEA with respect to half the claims i.e., with $C E A(E, \mathbf{c} / 2)$. He completed the rule for the case where the estate exceeds half of the sum of the claims. His rule does not satisfy independence of irrelevant claims or self-duality. Aumann and Maschler (1985) proposed a rule which is the unique self-dual rule that coincides with $C E A(E, \mathbf{c} / 2)$ on all problems with $E \leq C / 2$. This rule is also independent of irrelevant claims, and therefore by Proposition 2 coincides with the $\mathrm{CG}$ principle on two-creditor problems. Rabbi Hai Gaon suggested that Rabbi Nathan's recommendations are related to the CG principle ${ }^{13}$. Aumann and Maschler (1985) have shown that in any $n$-creditor problem their rule is the unique rule that assigns each two creditors $i$ and $j$ the awards $\left.\left(x_{i}, x_{j}\right)=C G\left(x_{i}+x_{j}, c_{i}, c_{j}\right)\right)$.

\section{Conclusion}

This paper provides axiomatic characterizations of two Talmudic bankruptcy rules. We believe that in addition to providing insight into these rules, the results provide support for the idea that legal problems may be analyzed by gametheoretic tools, and especially by an axiomatic approach.

In addition to the related work mentioned in the introduction and throughout the paper, we note that the rule described in Rashi's interpretation of Rabina was axiomatically treated by O'Neill (1982). Dagan and Voly (1993, Proposition 1) show that the CEA rule may be derived by applying the Nash bargaining solution to a bargaining problem associated with the bankruptcy problem. Dutta and Ray (1989, footnote 14) noted that applying their egalitarian solution to O'Neill's (1982) cooperative game associated with the bankruptcy problem will give the CEA rule.

A concept that was extensively studied in relation to the bankruptcy problem is that of self-consistency (see, e.g., Young, 1987). We do not discuss this property in this paper although the CEA rule is self-consistent, because we are interested in presenting axioms that relate to Talmudic principles, and feel that self-consistency is not such a property. The properties in our characterizations compare between bankruptcy problems with the same set of creditors, and thus the results hold even when considering rules that are defined on a domain of problems with a fixed set of creditors, whereas self-consistency is a non-empty requirement only when considering larger domains.

${ }^{13}$ We know about Hai Gaon's (939-1038) work from a quotation by Harif (Rabbi Yitshak Alfasi, 1013-1103). Gruner (1974, pp. 15-16) lists about thirty quotations of Hai Gaon's interpretation of Ketuboth that indicate that such an interpretation did exist. 
The axiom of independence of irrelevant claims admits another interpretation. The set of allocations in a bankruptcy problem is the same as in the problem where the claims are reduced to the relevant claims. Thus independence of irrelevant claims requires that the rule should be a function only of the set of allocations. Clearly, this interpretation was not inspired by Talmudic reasoning, but by modern game theory or bargaining theory.

\section{References}

Aumann RJ, Maschler M (1985) Game theoretic analysis of a bankruptcy problem from the Talmud. J Econ Theory 36: 195-213

Curiel IJ, Maschler M, Tijs SH (1988) Bankruptcy games. Z Op Res 31: A143-A159

Dagan N, Volij O (1993) The bankruptcy problem: a cooperative bargaining approach. Math Social Sciences 26: 287-297

Dutta B, Ray D (1989) A concept egalitarianism under participation constraints. Econometrica 57: $615-635$

Epstein I (Ed.) (1936) The Babylonian Talmud, Seder Nashim. Soncino Press, London

Gruner T (1974) Rav Hai Gaon: His Halachic Methodology, Ph.D. Thesis, The Hebrew University of Jerusalem, Jerusalem (in Hebrew)

Levine BM (Ed.) (1939) Otsar Hageonim. Mossad Harav Kuk, Jerusalem (in Hebrew)

O'Neill B (1982) A problem of rights arbitration from the Talmud. Math Social Sciences 2: 345-371

Pineles HM (1861) Darkah shel Torah. Forester, Vienna (in Hebrew)

Steinsaltz A (Ed.) (1985) The Babylonian Talmud. The Israel Institute for Talmudic Publications, Jerusalem (in Hebrew and Aramaic)

Young HP (1987) On dividing an amount according to individual claims or liabilities. Math Oper Res 12: 398-414

Young HP (1988) Distributive justice in taxation. J Econ Theory 44: 321-335 